\title{
Does avian conspicuous colouration increase or reduce predation risk?
}

\author{
M. Ruiz-Rodríguez $\cdot$ J. M. Avilés $\cdot$ J. J. Cuervo $\cdot$ D. Parejo $\cdot$ F. Ruano $\cdot$ \\ C. Zamora-Muñoz $\cdot$ F. Sergio $\cdot$ L. López-Jiménez $\cdot$ A. Tanferna $\cdot$ \\ M. Martín-Vivaldi
}

\begin{abstract}
Animals often announce their unprofitability to predators through conspicuous coloured signals. Here we tested whether the apparently conspicuous colour designs of the four European Coraciiformes and Upupiformes species may have evolved as aposematic signals, or whether instead they imply a cost in terms of predation risk. Because previous studies suggested that these species are unpalatable, we hypothesized that predators could avoid targeting them based on their colours. An experiment was performed where two artificial models of each bird species were exposed simultaneously to raptor predators, one painted so as to resemble the real colour design of these birds, and the other one painted using cryptic colours. Additionally, we used field data on the black kite's diet to compare the selection of these four species to that of other
\end{abstract}

Electronic supplementary material

article (doi:10.1007/s00442-013-2599-6) contains supplementary

material, which is available to authorized users.

M. Ruiz-Rodríguez $(\bowtie) \cdot$ J. M. Avilés · D. Parejo

Department of Functional and Evolutionary Biology,

Estación Experimental de Zonas Áridas (CSIC),

Almería, Spain

e-mail: magda@eeza.csic.es

J. J. Cuervo

Department of Evolutionary Ecology, Museo Nacional

de Ciencias Naturales (CSIC), Madrid, Spain

F. Ruano $\cdot$ C. Zamora-Muñoz $\cdot$ M. Martín-Vivaldi

Department of Zoology, Universidad de Granada,

Granada, Spain

F. Sergio · L. López-Jiménez · A. Tanferna

Department of Conservation Biology, Estación Biológica

de Doñana (CSIC), Seville, Spain avian prey. Conspicuous models were attacked in equal or higher proportions than their cryptic counterparts, and the attack rate on the four species increased with their respective degree of contrast against natural backgrounds. The analysis of the predator's diet revealed that the two least attacked species were negatively selected in nature despite their abundance. Both conspicuous and cryptic models of one of the studied species (the hoopoe) received fewer attacks than cryptic models of the other three species, suggesting that predators may avoid this species for characteristics other than colour. Globally, our results suggest that the colour of coraciiforms and upupiforms does not function as an aposematic signal that advises predators of their unprofitability, but also that conspicuous colours may increase predation risk in some species, supporting thus the handicap hypothesis.

Keywords Aposematism - Coraciiformes - Predator avoidance $\cdot$ Unprofitability $\cdot$ Upupiformes

\section{Introduction}

Predation exerts a high selective pressure on most animal species (Edmunds 1974; Caro 2005). Avoiding the attacks of predators is crucial for prey survival, and therefore any physical or behavioural trait that enhances the escape efficacy of prey will be favoured by natural selection (Langerhans 2007). An example of such a trait is antipredator colouration, which may function by either reducing or increasing prey detectability. On the one hand, cryptic species are difficult to detect by predators (Cott 1940) because their colouration is similar to that of the background (Endler 1978; Ruxton et al. 2004; Cuthill et al. 2005). On the other hand, species that invest in defences 
that make them unprofitable, often advertise their unpalatability by means of conspicuous signals such as sounds and/or odours, but more often exhibit exuberant colour patterns (Darwin 1871; Cott 1940; Dumbacher et al. 1992), which is known as aposematic colouration.

Indeed, it has been shown that conspicuous colour designs of unpalatable prey are more effective than cryptic colours in promoting predator avoidance (Mappes and Alatalo 1997), given that predators can rapidly learn the connection between such designs and unpalatability (e.g. Alatalo and Mappes 1996; Lindström et al. 1999; Riipi et al. 2001; Halpin et al. 2008; Lindstedt et al. 2009). As a result, aposematic colouration has evolved in several plant species (Lev-Yadun 2003; Lev-Yadun and Ne'eman 2004) and in a large variety of animal taxa (Götmark 1992; Stevens 2007; Maan and Cummings 2009).

In birds, the evidence of aposematism is scant and restricted to species belonging to the genera Pitohui, Ifrita (Dumbacher et al. 1992; Dumbacher and Pruett-Jones 1996; Dumbacher et al. 2000), and Ergaticus (Escalante and Daly 1994). These species exhibit flamboyant plumage colours in both sexes and accumulate in their skin and feathers highly toxic alkaloid substances, presumably obtained through their diet (Dumbacher et al. 2004). Although the advantage of bearing a conspicuous plumage in terms of predator avoidance has not been experimentally examined in these poisonous birds, it has been largely assumed that their high conspicuousness evolved as a warning signal of toxicity to potential predators (Dumbacher et al. 1992). In fact, conspicuous colour designs have been shown to be avoided by predators in other bird species. For instance, experiments with mounted specimens of a priori profitable species (pied flycatcher, Ficedula hypoleuca) exposed to migrating diurnal raptors, showed that predators attacked cryptic females more often than conspicuous males (Götmark 1993). However, to our knowledge, no study has yet demonstrated that conspicuous colouration provides any survival value, in terms of predation avoidance, to unpalatable species of birds.

The closely related orders Coraciiformes and Upupiformes (Mayr 2008) include highly conspicuous bird species displaying colourful plumage (at least to the human eye) in both sexes. Moreover, coraciiform and upupiform species have consistently been classified among the most distasteful species in comparative studies of bird edibility (Götmark 1994; Weldon and Rappole 1997). In this study, we tested whether such colouration can function as an aposematic signal in the three coraciiform (Eurasian roller, Coracias garrulus; bee-eater, Merops apiaster; and kingfisher, Alcedo atthis), and the only upupiform (hoopoe, Upupa epops) species breeding in Western Europe. Several pieces of evidence suggest that all these four species might be unprofitable:
1. Rollers consume a large share of poisonous arthropods (Avilés and Parejo 1997, 2002) that are avoided by most of the other sympatric insectivorous birds (Fry 2001).

2. Bee-eaters are specialized in the consumption of poisonous bees (Cramp and Perrins 1998). Thus, rollers and bee-eaters may potentially ingest the venomous glands of their prey and incorporate their poison into their tissues, in the same way that Pitoui and Ifrita species do (e.g. Dumbacher et al. 2004).

3. Kingfishers have been found to be unpalatable in several studies (Cott 1947; Weldon 2000). Furthermore, they may be an unprofitable prey to pursue because of their extremely quick flight, which can be signalled through conspicuous colours as a particular form of aposematism (Baker and Parker 1979; Götmark 1992; Ruxton et al. 2004; Mappes et al. 2005) and act as a pursuit-deterrence signal (Murphy 2006).

4. Hoopoes score among the most unpalatable birds in surveys of edibility (Götmark 1994), and further evidence suggests the use of chemical defences by this species. Firstly, breeding females present volatile chemicals in their uropygial glands. These chemicals are mainly produced by the action of symbiotic bacteria (Martín-Vivaldi et al. 2010), and cause a characteristic strong smell in the nest. Several of the substances produced by these bacteria are known to possess a strong anti-bacterial function (Martín-Platero et al. 2006; Soler et al. 2008; Ruiz-Rodríguez et al. 2009) but could also be involved in anti-predator defence. Indeed, the odorous secretion of hoopoes has been suggested to function mainly against predators, since the exudation of a drop from their uropygial glands is a typical response to the entrance of a predator into the nest chamber (Krištin 2001).

All the above arguments suggest that the conspicuous plumage colouration of coraciiforms and upupiforms could have evolved as aposematic warning signals of unpalatability directed towards potential predators.

Here, we examined such hypothetical aposematic function through a combination of experiments and empirical observations conducted in Doñana National Park (southern Spain), which harbours dense raptor populations and can thus function as a high-predation risk scenario. In a first experimental approach, we exposed pairs of artificial bird models to predator attacks, one painted using the true colours of the actual species (treatment or conspicuous model) and the other with cryptic colours only (control or cryptic model). We developed the following framework of predictions: we predicted that under the assumption that conspicuous colouration reduces predation risk, predators would avoid the treatment model and preferentially attack 
the cryptic controls (prediction 1). This, coupled with the reported evidence of low palatability, would suggest that the colour designs of these birds may have evolved in part as an aposematic warning signal. On the contrary, if predation is affected solely by the probability of visual prey detection, attack rates should be concentrated on the more detectable species (i.e. those that stand out more against the natural background) (prediction 2). Alternatively, we considered the possibility that colouration does not represent the target cue for predation on these species, in which case we predicted that conspicuous and cryptic models would be attacked at the same rate (prediction 3).

To add realism and insight to the above experiment, we also examined the diet of black kites, Milvus migrans, in the same study area. This species was chosen because it was by far the most abundant raptor in the study plot and because it was the predator that most frequently attacked our experimental models, thus allowing us to test whether the colour design of the four species may have a role in kite predation. Data on kite diet composition were used to assess whether the occurrence of coraciiforms and upupiforms relative to that of other similarly sized potential prey (not reported as unpalatable species) differed from expectations according to their respective abundance.

\section{Materials and methods}

Study area

The experiment was performed during the spring and summer (April-July) 2008 and 2009 in the Natural Space of Doñana (a National and Natural Park in south-west Spain; $1,100 \mathrm{~km}^{2}$ ). The park is crossed by kilometres of wooden fences to restrict cattle movement, which offer plenty of poles on which birds frequently perch. Thus, by placing the models on the poles, we could easily imitate how birds naturally expose themselves to aerial predators.

Doñana is world-renowned for its dense predator populations. The raptor community is strongly dominated by black kites, whose population has been estimated at about 500 territorial pairs plus 500 non-breeding individuals (Sergio et al. 2009). The large size of both the kite population and of the area where our models were placed minimized the possibility that specific individuals learned that the models were not real birds. Also, kites are opportunistic predators with an extremely variable diet based on prey ranging from small $1-\mathrm{g}$ arthropods to $1-\mathrm{kg}$ rabbits caught as live prey (F. Sergio, unpublished data), and they can prey on flying or immobile animals. Such versatility is a convenient characteristic for our experimental design, given that generalist predators are less neophobic than specialist ones (Greenberg 1983).
Experimental bird models

Previous studies in which birds were exposed to raptors employed stuffed specimens (e.g. Götmark 1992, 1997). However, we could not find enough stuffed models to ensure a reasonable number of attacks, so we used plaster models resembling natural coraciiforms and upupiforms in size, shape and colour patterns. These models, handcrafted by a specialist (http://www.replica-animal.com/), were also preferred to stuffed specimens because they allowed higher standardisation of potentially confounding factors such as size, shape, or even posture that could signal different vulnerability between experimental treatments (Cresswell and Quinn 2004; Quinn and Cresswell 2004). Animal models of this kind have been successfully used in previous studies on predator-prey interactions and aposematic colouration in insects (reviewed in Exnerova et al. 2006), birds (Cresswell et al. 2003) and reptiles (Niskanen and Mappes 2005).

The paintings were made ad hoc by a professional manufacturer (Pinturas Antequera, Granada) using a combination of pigments that matched the colours of real birds, which were assessed with a spectrophotometer (see below). For each species, the cryptic model was identical in shape and size to the conspicuous one, but painted in brown tones so as to resemble the colour pattern of song thrushes Turdus philomelos. To test the degree of colour similarity obtained with this method, the reflectance spectra of painted models and museum specimens were compared. We obtained reflectance data with an Ocean Optics equipment [S2000 spectrometer connected to a deuteriumhalogen light (D2-W, mini) by a coaxial reflectance probe (QR-400-7-UV-vis) and the OOIBase32 operating software (Ocean Optics, Dunedin, FL)]. Figure 1 shows the reflectance spectra for the painted models and the associated museum specimens (obtained from the Natural History Museum of the EEZA-CSIC, Almería). Artificial models looked convincingly real (Fig. 1), to the point that some experienced ornithologists occasionally passing by during the experiments confused them with real birds.

Model detectability by visual predators

We calculated the detectability of the exposed models in their natural environments from the perspective of a diurnal raptor using the colour opponency model of Vorobyev and Osorio (1998), developed for the tetrachromatic visual system of birds in its log form (Vorobyev et al. 1998). Model calculations were performed with Avicol software version 3 (Gomez 2006). Previous work demonstrated that this model efficiently predicted avian visual discrimination under photopic conditions (Vorobyev and Osorio 1998; Goldsmith and Butler 2005; Avilés 2008; Cassey et al. 
Fig. 1 Reflectance spectra of the colouration of experimental models $(\mathbf{a}, \mathbf{c}, \mathbf{e}, \mathbf{g})$ and museum specimens $(\mathbf{b}, \mathbf{d}, \mathbf{f}, \mathbf{h})$ of the four species: hoopoes $(\mathbf{a}, \mathbf{b})$, rollers $(\mathbf{c}, \mathbf{d})$, bee-eaters $(\mathbf{e}, \mathbf{f})$ and kingfishers $(\mathbf{g}, \mathbf{h})$. The bird images are photographs of the real models used in the field experiments (see Electronic supplementary material for colour figure) (colour figure online)
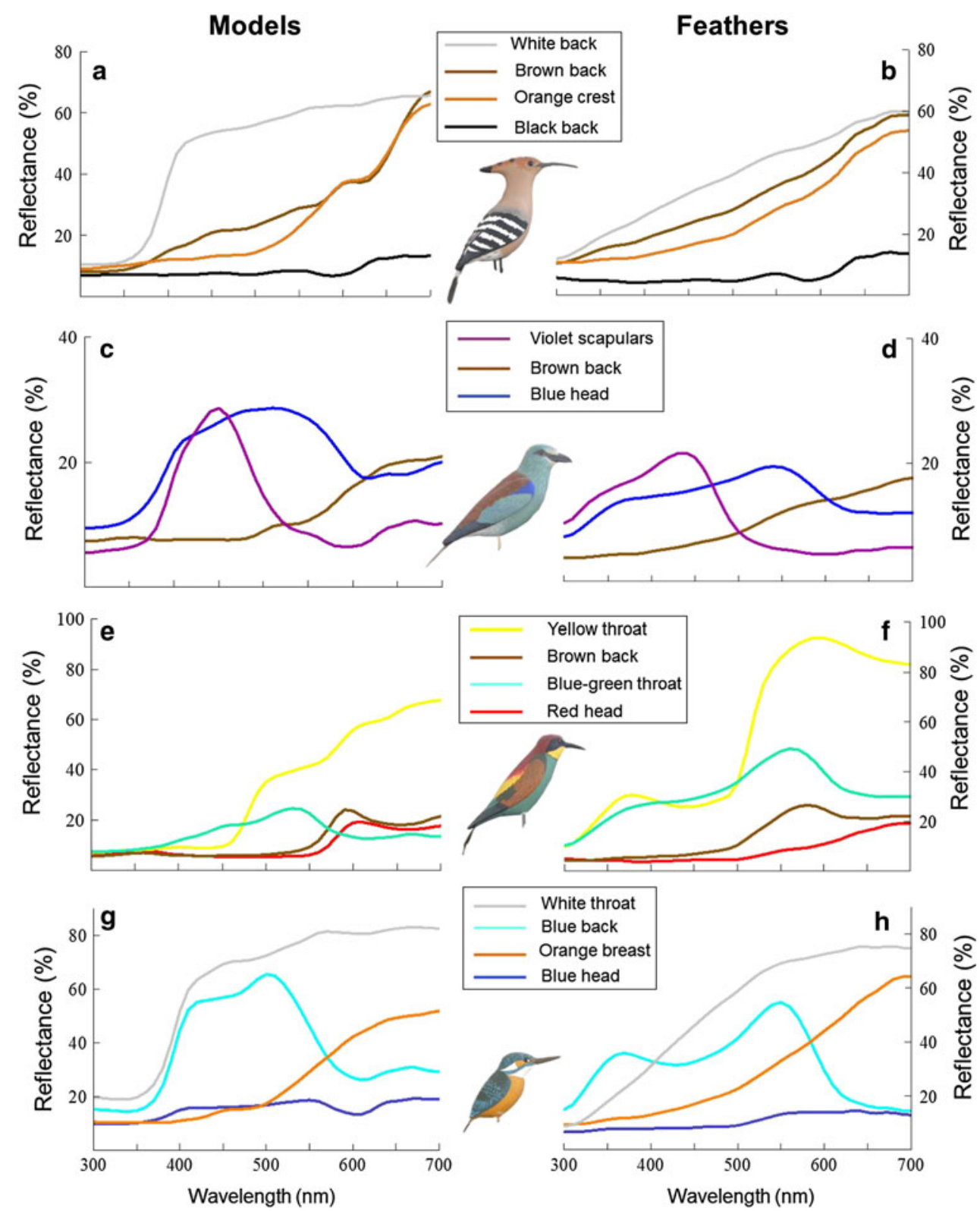

2008; Avilés et al. 2010). This model establishes a colour distance $(\Delta S)$ which describes the contrast between two coloured patches. When $\Delta S$ is less than 1 , the contrast is considered to be negligible, whereas when its value is over 1 , the contrast is considered to be discernible. This parameter is calculated as follows:

$$
\begin{aligned}
\Delta S^{2}= & {\left[\left(e_{1} e_{2}\right)^{2}\left(\Delta f_{4}-\Delta f_{3}\right)^{2}+\left(e_{1} e_{3}\right)^{2}\left(\Delta f_{4}-\Delta f_{2}\right)^{2}\right.} \\
& +\left(e_{1} e_{4}\right)^{2}\left(\Delta f_{2}-\Delta f_{3}\right)^{2}+\left(e_{2} e_{3}\right)^{2}\left(\Delta f_{4}-\Delta f_{1}\right)^{2} \\
& \left.+\left(e_{2} e_{4}\right)^{2}\left(\Delta f_{3}-\Delta f_{1}\right)^{2}+\left(e_{3} e_{4}\right)^{2}\left(\Delta f_{2}-\Delta f_{1}\right)^{2}\right] / \\
& \times\left[\left(e_{1} e_{2} e_{3}\right)^{2}+\left(e_{1} e_{2} e_{4}\right)^{2}+\left(e_{1} e_{3} e_{4}\right)^{2}+\left(e_{2} e_{3} e_{4}\right)^{2}\right]
\end{aligned}
$$

where $e_{i}$ is the $\mathrm{SD}$ of the noise in the receptor channel $i$, and $\Delta f_{\mathrm{i}}$ (see formula below) is the log ratio of the quantum catches of each class of single cones [long-wavelengthsensitive cones, medium wavelength sensitive, short wavelength sensitive (SWS), ultraviolet wavelength sensitive)] denoted by the subscript for cone $i$, for the first $(\mathrm{F})$ and second $(\mathrm{S})$ colour patch in a given contrast:

$\Delta f_{i}=\log \frac{\int_{300}^{700} R_{\mathrm{F}}(\lambda) I(\lambda) S(\lambda) \mathrm{d} \lambda}{\int_{300}^{700} R_{\mathrm{S}}(\lambda) I(\lambda) S(\lambda) \mathrm{d} \lambda}$

where $R_{\mathrm{F}}(\lambda)$ represents the average reflectance of the target plumage patch, $R_{\mathrm{S}}(\lambda)$ is the average reflectance of the contrasting elements, either yellow or green vegetation in this study, $I(\lambda)$ is the spectral irradiance, and $S(\lambda)$ is the spectral sensitivity of signal receptors $i$. Irradiance data were extracted from Avilés et al. (2008). Previous work suggests that diurnal raptors have a SWS1 opsin protein 
biased towards violet (Ödeen and Håstad 2003). Therefore, we computed a model for tetrachromatic vision with cone photoreceptor proportions of 1, 1.9, 2.2 and 2.1 after using spectral sensitivity data from the peafowl Pavo cristatus as representative of the violet sensitive system (Hart 2002; Håstad et al. 2005; Avilés and Soler 2009). Green and yellow-brown colours (from April to mid-June and from midJune to the end of July, respectively), constituted the main visual backgrounds against which the experimental models could be exposed in Doñana. Thus, we obtained reflectance data with the same Ocean Optics equipment described above on a representative sample of yellow-brown and green vegetation.

Our model assumed that photoreceptor noise was entirely based on neural noise, so for calculations we assumed that the signalling noise $\left(e_{\mathrm{i}}\right)$ for each cone was independent of light intensity:

$e_{i}=\omega / \sqrt{\eta_{i}}$

where $\omega$ is the Weber fraction (taken as 0.05 ; Vorobyev et al. 1998) and $\eta_{i}$ is the relative density of the cone class $i$ in the retina. We obtained chromatic contrasts between each species and the different colour patches of background vegetation (either green or yellow vegetation). This allowed us to assess the detectability of the target species over the full range of natural, seasonal backgrounds.

\section{Experimental design}

For every bird species, we compared the attack rate between the two associated treatment and control models (referred to as a "pair" hereafter). The two models of a pair were placed approximately 6-7 m apart and were tied to the top of existing fence poles. Models were set up in the morning (from 8 a.m. to 12 p.m.), and removed in the afternoon after being exposed to predators for $8 \mathrm{~h}$. Attacks and identity of the attacking predators were recorded by a camouflaged video camera placed in front of every pair (see online resources). Hereafter, each 8-h recording session of a pair is referred as an "experiment". Different experiments were separated by at least $500 \mathrm{~m}$. However, when a model was attacked at one location, no further experiments were conducted within $500 \mathrm{~m}$ of that site for the rest of the year. Usually, three experiments per species were conducted daily from May to July (i.e. approximately 12 experiments per day) except on rainy days. To avoid predators from learning that models were fake, we changed locations on consecutive days and took care not to re-use a given location unless a minimum of 4-5 days had lapsed. In addition, when a site was re-used, we always changed the identity of the experimental species that was exposed to predators.
Once a model of a pair was attacked (see online resources), none of the models were used again until their colours were reversed (conspicuous to cryptic and vice versa) by re-painting. Although both models in a pair were identical in shape and size and were assigned colours randomly, this protocol ensured that results were not confounded by any model feature different from colouration.

Importance of coraciiforms and upupiforms in the diet of black kites

We assessed the diet of locally breeding black kites, the predator responsible for most of the attacks (see below), in the same years of the experiment. We recorded prey remains at 138 kite nests in 2008, and 76 nests in 2009, as part of a long-term demographic study on this population (Sergio et al. 2011). Nests were visited from May to July, i.e. concurrently with the experiment. Remains were identified to the genus or species level, assuming the smallest possible number of individuals.

To test whether kites predated coraciiforms, upupiforms or other control species in relation to their availability, we estimated their field abundance by accessing the standardized avian survey data provided by the Doñana Biological Station's Monitoring Group of Natural Processes. In each survey, an experienced ornithologist walked slowly along a pre-defined $2.5-\mathrm{km}$ transect in the early morning, recording all avian species heard or observed. We included data from 16 line transects scattered throughout Doñana National Park in order to cover all its major macro-habitats. Although these surveys can underestimate the abundance of some species (Thompson 2002), the method is appropriate to assess the relative abundance of the species used in the selection index (see below) analyses given that they are easily detectable and recognizable both by sight and by their songs. Unfortunately, survey data were available in large enough sample sizes for two of the experimental species only: bee-eaters and hoopoes. Thus, rollers and kingfishers had to be discarded from the analyses of raptor diet.

We were interested in examining whether kites consumed coraciiform and upupiform species in proportion to their availability or whether, on the contrary, they attacked them less frequently than other control avian prey species that (1) possessed cryptic plumage, or (2) exhibited conspicuous plumage but were not known to be unpalatable. To obtain information on cryptic control species' availability and predation rates, we extracted kite diet and fieldsurvey data referring to any of the local species of the family Alaudidae and treated it together as a single group. For the conspicuous control species we extracted data on consumption of common magpies Pica pica and azurewinged magpies Cyanopica cyanus. To examine the 
occurrence of both prey types in the kites' diet relative to their availability, we used the Jacobs index (Jacobs 1974), calculated as $J=\left(U_{j}-D_{j}\right) /\left(U_{j}+D_{j}-2 U_{j} D_{j}\right)$, where: (1) $U_{j}=u_{i} / u_{+}, u_{i}$ being the number of observed items of prey type $i$, and $u_{+}$the total number or prey types considered; and (2) $D_{j}=d_{i} / d_{+}, d_{i}$ being the number of items of prey type $i$ available in the environment, and $d_{+}$the field availability of all prey types. The index ranges from -1 (maximum negative selection) to 1 (maximum positive selection), with zero indicating random selection of resources. This index is not associated with any particular statistical test, but it allows comparison of selection rates among groups.

\section{Statistical analyses}

Data on attack rates were pooled across years because results were consistent across field seasons (results not shown for brevity). Differences in attack rates between conspicuous and cryptic models were tested using binomial tests (Sokal and Rohlf 1995) in R software 2.13.1 ( $\mathrm{R}$ Development Core Team 2011). $\chi^{2}$-tests were used to compare attack rates between coraciiform and upupiform species. Overall differences among species were explored by combining the resultant $P$-values from the different tests following the formula:

$X_{k}=-2 \sum_{i=0}^{n}\left(\ln p_{i}\right)$

where $k$ is two times the number of different statistical analyses, and $P$ is the $P$-value of analysis $i$ (Sokal and Rohlf 1995). Statistical tests were carried out with the software STATISTICA 7.

\section{Results}

Attack rate on different models

A total of 994 pairs were exposed to predators in the 2 years of study. We recorded 111 attacks to the models, all of them by diurnal raptors. Of these, 93 were first attacks and 18 occurred after the first model in a pair had already been attacked. Because there could be no colour selection by predators in second attacks, only the 93 first attacks were used for analysis (Fig. 2). Although six raptor species attacked the models, predatory attempts were strongly dominated by black ( $56 \%$ of the attacks) and red kites Milvus milvus (35\%; Table 1).

The pairs of models of the four species were attacked at significantly different rates (combination of $P$-values from differences between pairs of species, $\chi^{2}=60.22, d f=12$,

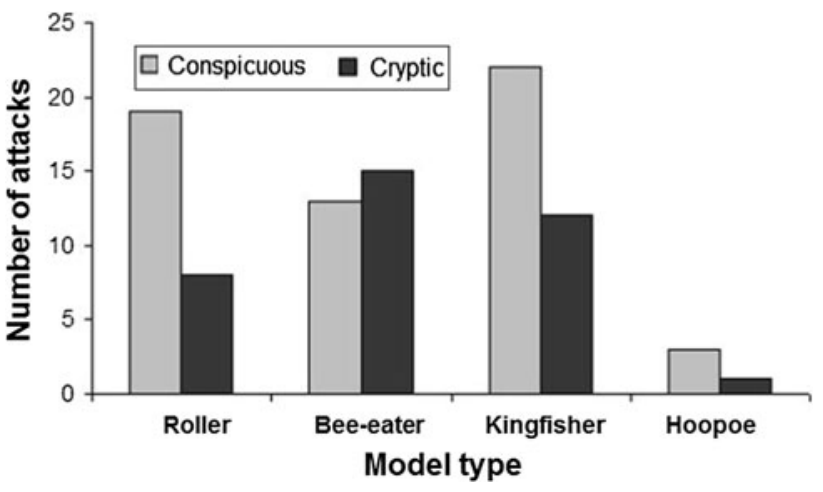

Fig. 2 Number of first attacks on paired conspicuous and cryptic models for each of the four study species

$P<0.0001)$. The hoopoe was the least frequently attacked species (only $2.2 \%$ of exposed pairs; Fig. 2). Pairwise comparisons of attack rates revealed significant differences between hoopoes and all three remaining species (kingfishers $14.3 \%$ of pairs, rollers $10.6 \%$, bee-eaters $8.7 \%$ ). The bee-eater was the second least-attacked species but only significantly less often than the kingfisher, the most attacked species. None of the other pairwise comparisons were significant (Table 2).

Hoopoe models received a total of four attacks by the end of the study. This small number offered too little power to allow for a proper analysis of the differences between conspicuous and cryptic models in this species. Among the other three prey species, the influence of colour of the model varied (Fig. 2). The treatment model was attacked significantly more often than the control pair in rollers (binomial test, $P=0.026, n=27$ ), and almost significantly so in the case of kingfishers (binomial test, $P=0.060, n=34$; Fig. 2). In contrast, attack rates on bee-eaters were not significantly different between models (binomial test, $P=0.71, n=28$ ).

To control for any species-specific sensory bias in raptors we repeated the previous analyses using data on black and red kites only, as these were the most frequent predators (Table 1). Black kites attacked treatment kingfisher models more frequently than control ones (binomial test: $P=0.014, n=20)$, while red kites attacked treatment roller models more often than control ones $(P=0.016$, $n=12$ ). There were no other significant differences between conspicuous and cryptic models. Moreover, no significant differences between black and red kites were found in the attack rates to any of the prey species $\left(\chi^{2}\right.$-tests, $P>0.3, d f=1$ in the four tests).

Detectability to predators

Visual modelling revealed that the roller was the most detectable (i.e. the highest chromatic contrast between any 
Table 1 Number of attacks recorded for each raptor species on different experimental models

\begin{tabular}{lccllll}
\hline & $\begin{array}{l}\text { Black } \\
\text { kite }\end{array}$ & $\begin{array}{l}\text { Red } \\
\text { kite }\end{array}$ & $\begin{array}{l}\text { Marsh } \\
\text { harrier }\end{array}$ & $\begin{array}{l}\text { Booted } \\
\text { eagle }\end{array}$ & $\begin{array}{l}\text { Eurasian } \\
\text { kestrel }\end{array}$ & $\begin{array}{l}\text { Common } \\
\text { buzzard }\end{array}$ \\
\hline $\begin{array}{l}\text { Hoopoe } \\
\text { Cryptic }\end{array}$ & 0 & 1 & 0 & 0 & 0 & 0 \\
$\begin{array}{l}\text { Conspicuous } \\
\text { Kingfisher }\end{array}$ & 1 & 1 & 0 & 0 & 1 & 0 \\
Cryptic & 5 & 5 & 0 & 0 & 1 & 1 \\
Conspicuous & 15 & 5 & 2 & 0 & 0 & 0 \\
Bee-eater & & & & & & 0 \\
Cryptic & 12 & 2 & 0 & 1 & 0 & 0 \\
Conspicuous & 6 & 7 & 0 & 0 & 0 & 0 \\
Roller & & & & & & 0 \\
Cryptic & 6 & 2 & 0 & 0 & 0 & 0 \\
Conspicuous & 7 & 10 & 0 & 2 & 0 & 0 \\
Total & 52 & 33 & 2 & 3 & 2 & 0 \\
\hline
\end{tabular}

Table $2 \chi^{2}$-tests comparing attack rates among the four coraciiform and upupiform species

\begin{tabular}{|c|c|c|c|c|c|c|}
\hline & \multicolumn{2}{|c|}{ Bee-eater } & \multicolumn{2}{|c|}{ Kingfisher } & \multicolumn{2}{|l|}{ Roller } \\
\hline & $\chi^{2}$ & $P$ & $\chi^{2}$ & $P$ & $\chi^{2}$ & $P$ \\
\hline Hoopoe & 8.18 & 0.004 & 18.4 & $<0.001$ & 12.05 & $<0.001$ \\
\hline Bee-eater & & & 4.5 & 0.034 & 0.89 & 0.34 \\
\hline Kingfisher & & & & & 1.21 & 0.27 \\
\hline
\end{tabular}

of its colours and the background) plaster model against both (green and yellow-brown) backgrounds, followed by the kingfisher, the bee-eater and the hoopoe (Fig. 3). The least contrasting models were the cryptic ones (those imitating the song thrush colour pattern).

Occurrence in real raptor diet

A total of 1,699 prey items were collected from 214 black kite nests. Avian prey represented $14.8 \%$ of the identified items. Only six items corresponded to coraciiform or upupiform species (three bee-eaters, two hoopoes and one roller), which represented $1.2 \%$ of the recorded avian prey and $0.2 \%$ of the total food items.

Selectivity analyses revealed a consistent pattern of negative selection on hoopoes $(J=-0.59)$ and bee-eaters $(J=-0.44)$, as well as for cryptic bird species (Alaudidae, $J=-0.58$ ), as opposed to a positive selection on other conspicuous prey (common magpies, $J=0.46$; azurewinged magpies, $J=0.68$ ) (Fig. 4).

\section{Discussion}

We found that artificial models imitating the natural colouration of four different bird species suffered different attack rates by wild raptors; models of kingfishers and rollers were the most attacked, followed by those of beeeaters and finally hoopoes. The models of kingfishers and rollers were also attacked significantly more often than models of the same species painted with cryptic colours. When we analysed conspicuousness against the natural background, models with the most visible patches (i.e. with a higher contrast against the background) were those imitating rollers, followed by kingfishers, then bee-eaters, hoopoes and finally the cryptic models of all species (see Fig. 3). These results suggest that differences in the attack rate to models could be the consequence of predators detecting conspicuous species more easily than cryptic ones, and support the hypothesis that, for rollers and kingfishers, conspicuous colouration is costly in terms of predation risk. Previous work revealed that in rollers, differences in several colour patches were related to quality and fitness in both sexes (Silva et al. 2008). Thus, the colouration of some coraciiforms might constitute a handicap (Zuk and Kolluru 1998; Zahavi and Zahavi 1999) as seems to be the case in other bird taxa (ColombelliNegrel and Kleindorfer 2010). Alternatively, predators could prefer the conspicuous models simply because they are more familiar with their appearance than with that of control models. Indeed, some studies suggest that predators tend to avoid novel prey (Götmark 1996). However, such neophobia has been typically associated with specialist predators (Greenberg 1983), and the raptors that attacked our models are generalist, opportunistic predators. Moreover, although in general raptors seemed to prefer the conspicuous models, cryptic ones were also attacked, not only when both models were exposed, but also as a second option, suggesting that raptors did not systematically avoid cryptic prey.

In bee-eaters, cryptic models and those imitating the real plumage colouration were attacked at similar rates, despite 
Fig. 3 Chromatic contrasts between the different body parts and the yellow-brown or green vegetation background for each of the four study species and their associated cryptic model

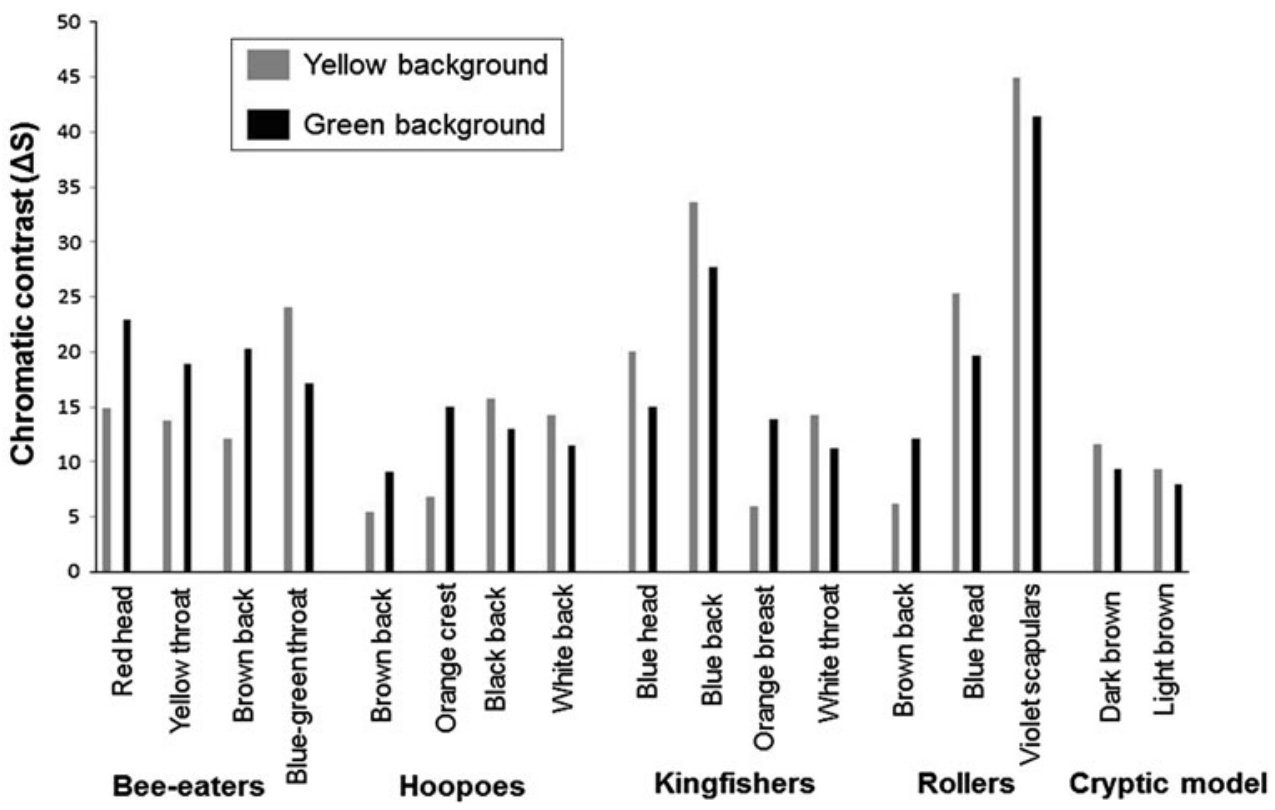

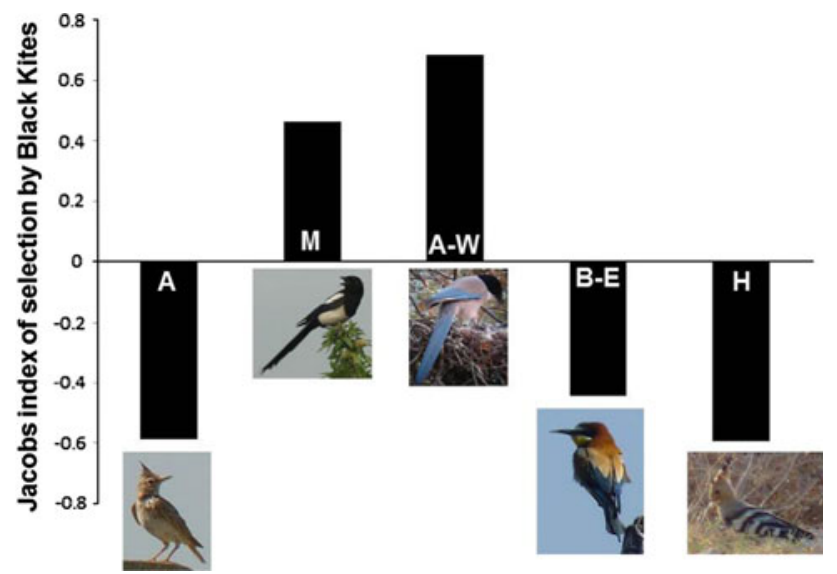

Fig. 4 Occurrence of conspicuous and cryptic avian prey in the diet of predatory black kites in Doñana National Park in 2008-2009. The Jacobs index compares the frequency of the target species with their field abundance in transect surveys: bee-eaters $(B-E)$, hoopoes $(H)$, other conspicuous birds ( $M$ common magpies, $A-W$ azure-winged magpies), and cryptic species (A Alaudidae) (photos of A, M, B-E and $\mathrm{H}$ by M. Ruiz-Rodríguez; A-W by C. de la Cruz)

the fact that their measured contrast against the background was slightly higher for coloured models. Therefore, although colourful individuals were not avoided, they were not preferentially attacked by predators either, so that in this case the colour design did not entail a cost in terms of predation risk (see Getty 2006). Though not yet studied in this particular species, plumage colour has been found to be a sexual ornament in other bee-eaters (Siefferman et al. 2007). Therefore, this could represent an example of a sexual ornament which does not necessarily entail a fitness cost to ensure signal honesty (Hill 2011), or alternatively, other costs than predation risk could maintain the ornament as an honest signal.
Interestingly, the two least attacked species' models turned out to represent the two most abundant species out of the four in Doñana, and thus those with which raptors had probably experienced more frequent encounters prior to the experiments. According to the data on the diet of black kites in Doñana, bee-eaters and hoopoes are consumed only rarely, resulting in negative selection. This means that predators could actually be avoiding these species, perhaps due to their unpalatability (see "Introduction") or because they are unprofitable prey for some other reason. However, because we did not find a higher attack rate on their cryptic counterparts, we cannot attribute their low presence in the diet to their colouration. Our results, therefore, do not provide sufficient evidence in this case to support the role of plumage colouration as an aposematic signal.

Methodological inaccuracies in the analysis of the diet could be argued to have led to unrealistic estimates of prey selection, i.e. negative selection could result from low species' identification probabilities in diet analyses. However, we are confident that the probability of failing to correctly identify the different species during diet analyses is almost zero, since identification is based on prey remains (e.g. mainly feathers), and thus the probability of identifying a bird is very similar for the different taxonomic groups. The negative selection of hoopoes and bee-eaters compared to that of common and azure-winged magpies could also be due to corvid species being more profitable. In fact, common magpies do have the largest body mass among these species. However, the average weight of azure-winged magpies $(70 \mathrm{~g})$ is very similar to that of hoopoes (69 g; Cramp and Perrins 1998), suggesting that, at least as far as these two species are concerned, the 
negative selection of hoopoes is not motivated by a lower nutritional value. Besides, the common magpie is the most aggressive and strongest bird of all at capture (M. R-R., personal observation), something that would in theory decrease the profitability of this prey. Other characteristics such as the ease of capture (i.e. profitability), or the behaviour of the target species, could also influence the risk of being predated.

Our results indicate that the colours of coraciiforms and upupiforms are not aposematic, despite them having been considered to act as warning signs of unpalatability in the literature up until now. A possible explanation for the lack of this sort of defence function against raptors in this group of species may be that palatability estimates cannot be transferred to birds. The reported evidence of unpalatability for these species comes from studies made with mammals and hornets (see "Introduction"). However, we cannot be sure that birds find these species equally distasteful, and thus cannot provide enough support for this explanation. As compared to other vertebrates, birds have relatively few taste buds which do not open directly into the oral cavity via taste pores, making the saliva a critical vehicle for the transport of taste stimuli to receptors (Masson and Clark 2000). However, avian taste is clearly functional given that birds can discriminate the palatability of different prey (Skelhorn and Rowe 2006a, b). Further experimental work is clearly needed so as to assess the similarity of mammalian and avian taste by comparing, for instance, the reaction of birds and mammals after offering them the same prey species.

Interestingly, hoopoe models and real hoopoes were attacked by raptors at very low rates. The models of this species suffered significantly fewer attacks than those of other species, while wild hoopoes were predated far less often than expected given their availability. Together, these results suggest that hoopoes are actively avoided by predators. However, the fact that both the cryptic and conspicuous hoopoe models were avoided suggests a negligible role of hoopoes' colour plumage in predator avoidance. We offer three non-exclusive explanations for such a pattern:

First, confronting our initial prediction, hoopoes could be difficult to detect by predators if their plumage was more cryptic than that of other species. Indeed, visual model calculations revealed that the hoopoe's colours show the least contrast against the vegetation background (Fig. 3). In addition, the black and white lines of the back of hoopoes could aid to break their perceived shape, constituting an example of disruptive colouration, which could explain their low detectability (Cott 1940; Stevens and Merilaita 2009).

Second, avian predators might have an innate aversion to combinations of colours commonly used in aposematic signalling, such as black with red or yellow (Ham et al. 2006). The hoopoe's plumage pattern of achromatic contrast (i.e. black and white) arranged in transversal lines (Fig. 1), is common in aposematic animals such as snakes and insects (Niskanen and Mappes 2005; Johansen et al. 2010). These two previous explanations are not necessarily exclusive, because the hoopoe's colours might be cryptic at some distance, but aposematic at a closer view, as found in some butterfly larvae (Tullberg et al. 2005; Bohlin et al. 2008). However, none of these explanations can account for the low attack rate experienced by the hoopoe cryptic models compared to the cryptic models of other species (Fig. 2).

Third, it is possible that some other characteristics of hoopoes, rather than colour alone, advertise unpalatability or general unprofitability, or even increase crypsis. For example, several traits and their combinations might be working simultaneously or hierarchically as aposematic signals, as shown in other species (Rowe and Guilford 1999; Exnerova et al. 2006). In our case, predators could have avoided hoopoes based on their very distinctive shape (being as it is the only local bird of that size with a long curved bill and a long crest). Moreover, the presence of the crest could help to disrupt the bird's silhouette, thereby reducing its detectability. Further manipulations of these different traits are needed to experimentally test such a hypothesis.

In conclusion, in two of the studied coraciiform species (roller and kingfisher), conspicuous colouration does not appear to function as an aposematic signal deterring predators but, on the contrary, is costly in terms of increased predation risk, which suggests it might potentially function as a signalling handicap. In the other two species (bee-eater and hoopoe), the natural colour design is equally effective as a cryptic brown colouration in avoiding predation. In the case of hoopoes, both colour and shape could be the cause of an extremely low predation rate, suggesting that predators may perceive and recognize hoopoes as an unprofitable prey based on a combination of traits, or alternatively that these traits make hoopoes hardly detectable.

Acknowledgments We thank all the volunteers who helped with fieldwork: R. Barrientos, G. Calvo, F. J. Chicano, M. García, O. Gordo, F. Goytre, M. Méndez, J. M. Peralta-Sánchez, M. J. Ruiz and J. J. Soler. M. Máñez, J. L. Arroyo, I. San Martín and the Equipo de Seguimiento de Procesos Naturales of the Estación Biológica de Doñana kindly provided access to their avian surveys. We thank all the personnel of the RBD for logistical support, and J. Moya for statistical advice. We also thank Dr James Dale and two anonymous referees for their straightforward suggestions that greatly improved the manuscript. The Consejería de Medio Ambiente of the Junta de Andalucía authorized our work within the areas with restricted access in the Natural Space of Doñana. This work was funded by projects RNM-02177 and RNM-03822 of the Junta de Andalucía, and CGL2008-01781 and CGL2010-19233-C03-03 of the Ministerio de Ciencia e Innovación. 


\section{References}

Alatalo RV, Mappes J (1996) Tracking the evolution of warning signals. Nature 382:708-710

Avilés JM (2008) Egg colour mimicry in the common cuckoo Cuculus canorus as revealed by modelling host retinal function. Proc R Soc Lond B 275:2345-2352

Avilés JM, Parejo D (1997) Dieta de los pollos de carraca (Coracias garrulus) en una zona mediterránea (Extremadura, suroeste de España). Ardeola 44:237-239

Avilés JM, Parejo D (2002) Diet and prey type selection by rollers (Coracias garrulus) during the breeding season in southwestern Iberian Peninsula. Alauda 70:227-230

Avilés JM, Soler JJ (2009) Nestling colouration is adjusted to parent visual performance in altricial birds. J Evol Biol 22:376-386

Avilés JM, Pérez-Contreras T, Navarro C, Soler JJ (2008) Dark nests and conspicuousness in color patterns of nestlings of altricial birds. Am Nat 171:327-338

Avilés JM, Vikan JR, Fossoy F, Antonov A, Moksnes A, Roskaft E, Stokke BG (2010) Avian colour perception predicts behavioural responses to experimental brood parasitism in chaffinches. J Evol Biol 23:293-301

Baker RR, Parker GA (1979) The evolution of bird colouration. Philos Trans R Soc Lond B 287:63-130

Bohlin T, Tullberg BS, Merilaita S (2008) The effect of signal appearance and distance on detection risk in an aposematic butterfly larva (Parnassius apollo). Anim Behav 76:577-584

Caro T (2005) Antipredator defenses in birds and mammals. Chicago University Press, Chicago

Cassey P, Honza M, Grim T, Hauber ME (2008) The modelling of avian visual perception predicts behavioural rejection responses to foreign egg colours. Biol Lett 4:515-517

Colombelli-Negrel D, Kleindorfer S (2010) Video nest monitoring reveals male coloration-dependant nest predation and sex differences in prey size delivery in a bird under high sexual selection. J Ornithol 151:507-512

Cott HB (1940) Adaptive coloration in animals. Methuen, London

Cott HB (1947) The edibility of birds: illustrated by 5 years' experiments and observations (1941-1946) on the food preferences of the hornet, cat and man; and considered with special reference to the theories of adaptive coloration. Proc Zool Soc Lond 116:371-524

Cramp S, Perrins C (1998) The complete birds of the Western Paleartic on CD-ROM. Oxford University Press, Oxford

Cresswell W, Quinn JL (2004) Faced with a choice, sparrowhawks more often attack the more vulnerable prey group. Oikos 104:71-76

Cresswell W, Lind J, Kaby U, Quinn JL, Jakobsson S (2003) Does a opportunistic predator preferentially attack nonvigilant prey? Anim Behav 66:643-648

Cuthill IC, Stevens M, Sheppard J, Maddocks T, Parraga CA, Troscianko TS (2005) Disruptive coloration and background pattern matching. Nature 434:72-74

Darwin C (1871) The descent of man and selection in relation to sex. Murray, London

Dumbacher JP, Pruett-Jones S (1996) Avian chemical defense. In: Nolan V, Ketterson ED (eds) Current ornithology. Plenum, New York, pp 137-174

Dumbacher JP, Beehler BM, Spande TF, Garraffo HM (1992) Homobatrachotoxin in the genus Pitohui: chemical defense in birds? Science 258:799-801

Dumbacher JP, Spande TF, Daly JW (2000) Batrachotoxin alkaloids from passerine birds: a second toxic bird genus (Ifrita kowaldi) from New Guinea. Proc Natl Acad Sci USA 97:12970-12975

Dumbacher JP, Wako A, Derrickson SR, Samuelson A, Spande TF, Daly JW (2004) Melyrid beetles (Choresine): a putative source for the batrachotoxin alkaloids found in poison-dart frogs and toxic passerine birds. Proc Natl Acad Sci USA 101:15857-15860

Edmunds M (1974) Defence in animals: a survey of antipredator defences. Longman, Harlow

Endler J (1978) A predator's view of animal colour patterns. Evol Biol 11:319-364

Escalante P, Daly JW (1994) Alkaloids in extracts of feathers of the red-warbler. J Ornithol 135:410

Exnerova A, Svadova K, Stys P, Barcalova S, Landova E, Prokopova M, Fuchs R, Socha R (2006) Importance of colour in the reaction of passerine predators to aposematic prey: experiments with mutants of Pyrrhocoris apterus (Heteroptera). Biol J Linn Soc $88: 143-153$

Fry CH (2001) Family Coraciidae (rollers). In: del Hoyo J, Elliot A, Sargatal J (eds) Handbook of the birds of the world. Mousebirds to hornbills. Lynx, Barcelona, pp 342-377

Getty T (2006) Sexually selected signals are not similar to sports handicaps. Trends Ecol Evol 21:83-88

Goldsmith TH, Butler BK (2005) Color vision of the budgerigar (Melopsittacus undulatus): hue matches, tetrachromacy, and intensity discrimination. J Comp Physiol 191:933-951

Gomez D (2006) AVICOL, a program to analyse spectrometric data. http://sites.google.com/site/avicolprogram/

Götmark F (1992) Antipredator effect of conspicuous plumage in a male bird. Anim Behav 44:51-55

Götmark F (1993) Conspicuous coloration in male birds is favored by predation in some species and disfavoured in others. Proc R Soc Lond B 253:143-146

Götmark F (1994) Are bright birds distasteful? A reanalysis of H. B. Cott's data on the edibility of birds. J Avian Biol 25:184-197

Götmark F (1996) Simulating a colour mutation: conspicuous red wings in the European blackbird reduce the risk of attacks by sparrowhawks. Funct Ecol 10:355-359

Götmark F (1997) Bright plumage in the magpie: does it increase or reduce the risk of predation? Behav Ecol Sociobiol 40:41-49

Greenberg R (1983) The role of neophobia in determining the degree of foraging specialization in some migrant warblers. Am Nat 122:444-453

Halpin CG, Skelhorn J, Rowe C (2008) Being conspicuous and defended: selective benefits for the individual. Behav Ecol 19:1012-1017

Ham AD, Ihalainen E, Lindström L, Mappes J (2006) Does colour matter? The importance of colour in avoidance learning, memorability and generalisation. Behav Ecol Sociobiol 60: $482-491$

Hart NS (2002) Vision in the peafowl (Aves: Pavo cristatus). J Exp Biol 205:3925-3935

Håstad O, Victorsson J, Ödeen A (2005) Differences in color vision make passerines less conspicuous in the eyes of their predators. Proc Natl Acad Sci USA 102:6391-6394

Hill GE (2011) Condition-dependent traits as signals of the functionality of vital cellular processes. Ecol Lett 14:625-634

Jacobs J (1974) Quantitative measurement of food selection. A modification of the forage ratio and Ivlev's electivity index. Oecologia 14:413-417

Johansen AI, Exnerova A, Svadova KH, Stys P, Gamberale-Stille G, Tullberg BS (2010) Adaptive change in protective coloration in adult striated shieldbugs Graphosoma lineatum (Heteroptera: Pentatomidae): test of detectability of two colour forms by avian predators. Ecol Entomol 35:602-610

Krištin A (2001) Family Upupidae (hoopoe). In: del Hoyo J, Elliot A, Sargatal J (eds) Handbook of the birds of the world. Mousebirds to hornbills. Lynx, Barcelona, pp 396-411

Langerhans RB (2007) Evolutionary consequences of predation: avoidance, escape, reproduction, and diversification. In: Elewa 
AMT (ed) Predation in organisms: a distinct phenomenon. Springer, Heidelberg, pp 177-220

Lev-Yadun S (2003) Weapon (thorn) automimicry and mimicry of aposematic colorful thorns in plants. J Theor Biol 224:183-188

Lev-Yadun S, Ne'eman G (2004) When may green plants be aposematic? Biol J Linn Soc 81:413-416

Lindstedt C, Lindström L, Mappes J (2009) Thermoregulation constrains effective warning signal expression. Evolution 63: $469-478$

Lindström L, Alatalo RV, Mappes J, Riipi M, Vertainen L (1999) Can aposematic signals evolve by gradual change? Nature 397: 249-251

Maan ME, Cummings ME (2009) Sexual dimorphism and directional sexual selection on aposematic signals in a poison frog. Proc Natl Acad Sci USA 106:19072-19077

Mappes J, Alatalo RV (1997) Batesian mimicry and signal accuracy. Evolution 51:2050-2053

Mappes J, Marples N, Endler JA (2005) The complex business of survival by aposematism. Trends Ecol Evol 20:598-603

Martín-Platero AM, Valdivia E, Ruiz-Rodríguez M, Soler JJ, MartínVivaldi M, Maqueda M, Martínez-Bueno M (2006) Characterization of antimicrobial substances produced by Enterococcus faecalis MRR 10-3, isolated from the uropygial gland of the hoopoe (Upupa epops). Appl Environ Microbiol 72:4245-4249

Martín-Vivaldi M, Peña A, Peralta-Sánchez JM, Sánchez L, Ananou S, Ruiz-Rodríguez M, Soler JJ (2010) Antimicrobial chemicals in hoopoe preen secretions are produced by symbiotic bacteria. Proc R Soc Lond B 277:123-130

Masson JR, Clark L (2000) The chemical senses in birds. In: Whittow G (ed) Sturkie's avian physiology. Academic Press, New York, pp 39-56

Mayr G (2008) Avian higher-level phylogeny: well supported clades and what we can learn from a phylogenetic analyses of 2954 morphological characters. J Zool Syst Evol Res 46:63-72

Murphy TG (2006) Dishonest "preemptive" pursuit-deterrent signal? Why the turquoise-browed motmot wags its tail before feeding nestlings. Anim Behav 73:965-970

Niskanen M, Mappes J (2005) Significance of the dorsal zigzag pattern of Vipera latastei gaditana against avian predators. J Avian Biol 74:1091-1101

Ödeen A, Håstad O (2003) Complex distribution of avian color vision systems revealed by sequencing the SWS1 opsin from total DNA. Mol Biol Evol 20:855-861

Quinn JL, Cresswell W (2004) Predator hunting behavior and prey vulnerability. J Anim Ecol 73:143-154

R Development Core Team (2011) R: a language and environment for statistical computing. R Foundation for Statistical Computing, Vienna. http://www.R-project.org

Riipi M, Alatalo RV, Lindström L, Mappes J (2001) Multiple benefits of gregariousness cover detectability costs in aposematic aggregations. Nature 413:512-514

Rowe C, Guilford T (1999) The evolution of multimodal warning displays. Evol Ecol 13:655-671

Ruiz-Rodríguez M, Valdivia E, Soler JJ, Martín-Vivaldi M, MartínPlatero AM, Martínez-Bueno M (2009) Symbiotic bacteria living in the hoopoe's uropygial gland prevent feather degradation. J Exp Biol 212:3621-3626

Ruxton GD, Speed M, Sherratt TN (2004) Evasive mimicry: when (if ever) could mimicry based on difficulty of capture evolve? Proc R Soc Lond B 271:2135-2142

Sergio F, Blas J, Hiraldo F (2009) Predictors of floater status in a long-lived bird: a cross-sectional and longitudinal test of hypotheses. J Anim Ecol 78:109-118

Sergio F, Blas J, Blanco G, Tanferna A, López L, Lemus J, Hiraldo F (2011) Raptor nest decorations are a reliable threat against conspecifics. Science 331:327-330

Siefferman L, Wang YJ, Wang YP, Yuan HS (2007) Sexual dichromatism, dimorphism, and condition-dependent coloration in blue-tailed bee-eaters. Condor 109:577-584

Silva N, Avilés JM, Danchin E, Parejo D (2008) Informative content of multiple plumage-coloured traits in female and male European rollers. Behav Ecol Sociobiol 62:1969-1979

Skelhorn J, Rowe C (2006a) Avian predators taste-reject aposematic prey on the basis of their chemical defence. Biol Lett 2:348-350

Skelhorn J, Rowe C (2006b) Taste-rejection by predators and the evolution of unpalatability in prey. Behav Ecol Sociobiol 60: $550-555$

Sokal RR, Rohlf FJ (1995) Biometry, 3rd edn. Freeman, San Francisco

Soler JJ, Martín-Vivaldi M, Ruiz-Rodríguez M, Valdivia E, MartínPlatero AM, Martínez-Bueno M, Peralta-Sánchez JM, Méndez M (2008) Symbiotic association between hoopoes and antibioticproducing bacteria that live in their uropygial gland. Funct Ecol 22:864-871

Stevens M (2007) Predator perception and the interrelation between different forms of protective coloration. Proc R Soc Lond B 274:1457-1464

Stevens M, Merilaita S (2009) Defining disruptive colouration and distinguishing its functions. Philos Trans R Soc Lond B 364:481-488

Thompson WL (2002) Towards reliable bird surveys: accounting for individuals present but not detected. Auk 119:18-25

Tullberg BS, Merilaita S, Wiklund C (2005) Aposematism and crypsis combined as a result of distance dependence: functional versatility of the colour pattern in the swallowtail butterfly larva. Proc R Soc Lond B 272:1315-1321

Vorobyev M, Osorio D (1998) Receptor noise as a determinant of colour thresholds. Proc R Soc Lond B 265:351-358

Vorobyev M, Osorio D, Bennett ATD, Marshall NJ, Cuthill IC (1998) Tetrachromacy, oil droplets and bird plumage colours. J Comp Physiol 183:621-633

Weldon PJ (2000) Avian chemical defense: toxic birds not of a feather. Proc Natl Acad Sci USA 97:12948-12949

Weldon PJ, Rappole JH (1997) A survey of birds odorous or unpalatable to humans: possible indications of chemical defense. J Chem Ecol 23:2609-2633

Zahavi A, Zahavi A (1999) The handicap principle: a missing piece of Darwin's puzzle. Oxford University Press, New York

Zuk M, Kolluru GR (1998) Exploitation of sexual signals by predators and parasitoids. Q Rev Biol 73:415-438 